\title{
Effect of WW Domain-Containing Oxidoreductase Gene Polymorphism on Clinicopathological Characteristics of Patients with EGFR Mutant Lung Adenocarcinoma in Taiwan
}

\author{
Ju-Pi Li 1,2@, Jinghua Tsai Chang ${ }^{3,4}$, Po-Chung Ju 1,5, Ming-Hong Hsieh 1,5 $\left(\mathbb{D}\right.$, Yu-Hua Chao ${ }^{1,2}$, \\ Thomas Chang-Yao Tsao ${ }^{1,6}$, Ming-Ju Hsieh ${ }^{7,8,9, *(1)}$ and Shun-Fa Yang ${ }^{3,4, * \mathbb{C}}$
}

1 School of Medicine, Chung Shan Medical University, Taichung 402, Taiwan; jupili@csmu.edu.tw (J.-P.L.); cshy841@csh.org.tw (P.-C.J.); mhhpsy@hotmail.com (M.-H.H.); nka6150@gmail.com (Y.-H.C.); his885889@gmail.com (T.C.-Y.T.)

2 Department of Pediatrics, Chung Shan Medical University Hospital, Taichung 402, Taiwan

3 Institute of Medicine, Chung Shan Medical University, Taichung 402, Taiwan; jinghuat@csmu.edu.tw

4 Department of Medical Research, Chung Shan Medical University Hospital, Taichung 402, Taiwan

5 Department of Psychiatry, Chung Shan Medical University Hospital, Taichung 402, Taiwan

6 Division of Chest, Department of Internal Medicine, Chung Shan Medical University Hospital, Taichung 402, Taiwan

7 Oral Cancer Research Center, Changhua Christian Hospital, Changhua 500, Taiwan

8 Graduate Institute of Biomedical Sciences, China Medical University, Taichung 404, Taiwan

Citation: Li, J.-P.; Chang, J.T.; Ju, P.-C.; Hsieh, M.-H.; Chao, Y.-H.; Tsao, T.C.-Y.; Hsieh, M.-J.; Yang, S.-F. Effect of WW Domain-Containing

Oxidoreductase Gene Polymorphism on Clinicopathological Characteristic of Patients with EGFR Mutant Lung Adenocarcinoma in Taiwan. Int. J. Environ. Res. Public Health 2021, 18, 13136. https://doi.org/10.3390/ ijerph182413136

Academic Editor: Paul B. Tchounwou

Received: 4 November 2021

Accepted: 11 December 2021

Published: 13 December 202

Publisher's Note: MDPI stays neutral with regard to jurisdictional claims in published maps and institutional affiliations.

Copyright: () 2021 by the authors. Licensee MDPI, Basel, Switzerland. This article is an open access article distributed under the terms and conditions of the Creative Commons Attribution (CC BY) license (https:// creativecommons.org/licenses/by/ $4.0 /)$.
9 College of Medicine, National Chung Hsing University, Taichung 402, Taiwan

* Correspondence: 170780@cch.org.tw (M.-J.H.); ysf@csmu.edu.tw (S.-F.Y.)

\begin{abstract}
Lung adenocarcinoma is the most common histological type of non-small cell lung cancer, which accounts for the majority of lung cancers. Previous studies have showed that dysregulation of WW domain-containing oxidoreductase (WWOX) participates in the generation of several cancer types, including lung cancer. However, whether these WWOX polymorphisms are related to the clinical risk of epidermal growth factor receptor (EGFR)-mutated lung adenocarcinoma is worthy of investigation. The present study examined the relationship between the WWOX single-nucleotide polymorphisms (SNPs; rs11545028, rs12918952, rs3764340, rs73569323, and rs383362) and the clinicopathological factors in lung adenocarcinoma patients with or without EGFR mutations. We found that there was no significant difference in the genotype distribution of WWOX polymorphism between EGFR wild-type and EGFR mutant in patients with lung adenocarcinoma. Our results demonstrated that the presence of at least one G genotype (CG and GG) allele on WWOX rs3764340 was associated with a significantly higher risk of nearby lymph node involvement in those patients harboring EGFR mutations (odds ratio $(\mathrm{OR})=3.881, p=0.010$ ) compared with the CC genotype. Furthermore, in the subgroup of lung adenocarcinoma patients with the EGFR-L858R mutation, both WWOX rs3764340 $\mathrm{C} / \mathrm{G}(\mathrm{OR}=5.209, p=0.023)$ and $\mathrm{rs} 73569323 \mathrm{C} / \mathrm{T}$ polymorphisms $(\mathrm{OR}=3.886, p=0.039)$ exhibited significant associations with the size of primary tumors and the invasion of adjacent tissues. In conclusion, these data indicate that WWOX SNPs may help predict tumor growth and invasion in patients with EGFR mutant lung adenocarcinoma, especially those with the EGFR-L858R mutant in Taiwan.
\end{abstract}

Keywords: lung cancer; WWOX; polymorphism; EGFR mutation

\section{Introduction}

Lung cancer has a higher incidence and mortality rate among cancers in the world [1]. There are two main types of lung cancer: non-small cell lung cancer (NSCLC) and small cell lung cancer. NSCLCs account for approximately $80 \%$ to $85 \%$ of lung cancers, and adenocarcinoma is the most common histological type of NSCLC. Many risk factors are currently known to cause lung cancer, among which mutations in the epidermal growth 
factor receptor (EGFR) gene have been shown to be related to more than $60 \%$ of NSCLCs [2]. EGFR tyrosine kinase inhibitors (TKIs) have been introduced into the first-line treatment of NSCLCs to improve treatment efficacy and overall survival [3]. The short in-frame deletions of exon 19 (Exon19 in-frame deletion) mutation and the single-point substitution of leucine by arginine at codon 858 (L858R) mutation are located in the tyrosine kinase domain and account for approximately $90 \%$ of all EGFR mutations in lung adenocarcinoma $[4,5]$. Although EGFR kinase mutations are associated with increased sensitivity to TKIs, not all cancers with these mutations are associated with increased therapeutic outcomes. Therefore, it is important to further analyze whether additional genetic variants are synergistically involved in these lung adenocarcinoma patients with EGFR mutations.

The WW domain-containing oxidoreductase (WWOX) gene is mapped to human chromosome 16q23.3-24.1, which spans approximately 1.1 megabases and consists of nine exons and eight introns $[6,7]$. The WWOX gene encompasses the FRA16D fragile region, which frequently undergoes chromosomal breaks and rearrangements in cancers [8-10]. The WWOX gene mainly encodes a protein of 414 amino acids $(46 \mathrm{kDa})$. Its $\mathrm{N}$-terminal region contains two tandem WW domains and its C-terminal region contains a catalytic domain homologous to short-chain dehydrogenase/reductase family proteins [11]. The WWOX protein has been shown to participate in a variety of cellular processes, such as DNA damage responses, cellular metabolism, and tumor suppression [7,12-14]. Over time, numerous studies support that WWOX exerts tumor suppressor effects through specific molecular actions that are mostly cell type specific [15]. Dysregulation of WWOX not only leads to tumorigenesis and cancer progression, but also causes genome instability and treatment difficulties [16]. The reduction or absence of WWOX expression has been found to be associated with several cancers, such as breast cancers, thyroid cancer, oral cancer, lung cancer, and so on [8,17-22].

Furthermore, it is known that genetic variants, such as single nucleotide polymorphisms (SNPs), are highly correlated with cancer susceptibility [23]. Several WWOX SNPs, including rs11545028, rs12918952, rs3764340, and rs383362, have been demonstrated to act as a potential risk factor for various malignant cancers [20,24-26]. In contrast, WWOX rs73569323 SNP is negatively associated with the risk of hepatocellular carcinoma [26]. Therefore, whether these WWOX polymorphisms are related to the clinical risk of EGFRmutated lung adenocarcinoma is worthy of investigation. In the present study, we evaluated the effects of WWOX polymorphisms, including rs11545028, rs12918952, rs3764340, rs73569323 and rs383362, on lung adenocarcinoma with wild-type and mutant EGFR. In addition, we assessed the associations between WWOX SNPs and the clinicopathological factors in lung adenocarcinoma patients with or without EGFR mutations.

\section{Materials and Methods}

\subsection{Patients and Specimens}

A total of 316 patients with lung adenocarcinoma were recruited at Chung Shan Medical University Hospital, Taiwan. All patient data, including gender, age and exposure to exogenous risk factors, such as smoking status, were obtained from medical records and questionnaires. Genomic DNA was collected from tumor specimens or whole blood specimens for EGFR gene sequencing or WWOX genotyping, respectively. Lung adenocarcinoma is staged at the time of diagnosis according to the tumor/lymph node/metastasis (TNM) classification of malignant tumors of the American Joint Committee on Cancer. The size of the primary tumor and the invasion of adjacent tissues are described as T, T1-T4; the regional lymph nodes' status is described as $\mathrm{N}$; and distant metastasis is described as $M$ [27]. The study protocol was approved by the Institutional Review Board of Chung Shan Medical University Hospital (No. CS1-20144, 24 August 2020). Each participating patient provided a signed informed consent form before the start of the study. 


\subsection{EGFR Gene Sequencing}

Genomic DNA was extracted from the tumor tissues of patients with lung adenocarcinoma using the QIAamp Fast DNA Tissue Kit (Qiagen, Valencia, CA, USA) according to the manufacturer's instructions. Exons 18-21 of the EGFR gene were amplified using the polymerase chain reaction (PCR) and were then subjected to the DNA sequencing reaction using the ABI PRISM 3130XL System (Applied Biosystems, Foster City, CA, USA) as described previously [28].

\subsection{Genotyping of WWOX Polymorphisms}

Genomic DNA was collected from whole-blood specimens of patients with lung adenocarcinoma using the QIAamp DNA Blood Mini Kit (Qiagen, Valencia, CA, USA) according to the manufacturer's protocols. The allelic identification of five WWOX polymorphisms (rs11545028, rs12918952, rs3764340, rs73569323 and rs383362) was examined using the TaqMan SNP genotyping assay and the ABI StepOnePlus Real-Time PCR system (Applied Biosystems, Foster City, CA, USA). For a negative control, each PCR reaction used distilled water instead of DNA in the reaction system.

\subsection{Statistical Analysis}

The Mann-Whitney U test and Fisher's exact test were used to compare the differences in clinical characteristics and genotype distribution frequencies between lung adenocarcinoma patients harboring the EGFR wild-type or mutation type in this study. Multiple logistic regression models after controlling for other variables were used to estimate the odds ratios (ORs) with corresponding 95\% confidence intervals (CIs) of the association between the genotype frequencies and risk of EGFR types. All data were analyzed using SAS software, version 9.1 (SAS Institute Inc., Cary, NC, USA). A $p$-value less than 0.05 was used to indicate statistical significance.

\section{Results}

\subsection{Characteristics of Study Participants}

To explore the effects of WWOX polymorphisms on lung adenocarcinoma risk, a total of 316 lung adenocarcinoma patients were enrolled. These lung adenocarcinoma patients were divided into patients with EGFR wild type $(n=127,40.2 \%)$ and patients with EGFR mutation $(n=189,59.8 \%)$ based on EGFR sequencing data. Table 1 showed the clinical characteristics of these enrolled patients. The significant differences in gender $(p<0.001)$ and cigarette smoking status $(p<0.001)$ were observed between the patients with lung adenocarcinoma with the EGFR wild type and those with the EGFR mutation (Table 1). Compared with the EGFR wild type group, there were more female patients $(n=120,63.5 \%)$ and never smokers $(n=145,76.7 \%)$ in the EGFR mutant group (Table 1$)$. The significance was not observed between groups in the other clinical characteristics, such as age, tumor stage, tumor T status, lymph node status, and distant metastasis (Table 1).

\subsection{Distribution Frequency of WWOX Genotypes in Lung Adenocarcinoma Patients}

Whole-blood specimens from the recruited 316 patients were collected and examined for the five WWOX genotype distribution frequencies (rs11545028, rs12918952, rs3764340, rs73569323 and rs383362). The genotype distributions and associations of WWOX gene between the lung adenocarcinoma patients with the EGFR wild type and those with the EGFR mutation were shown in Table 2. In these lung adenocarcinoma patients, whether it was EGFR wild type or mutation, the alleles with the highest distribution frequency at rs11545028, rs12918952, rs3764340, rs73569323 and rs383362 were homozygous for CC, homozygous for GG, homozygous for CC, homozygous for CC, and homozygous for GG, respectively. In order to minimize the interference of confounding variables, a multiple logistic regression model was used to estimate the adjusted odds ratio (AOR) with a 95\% confidence interval (CI) after adjusting for variances such as age and smoking habits. Table 2 showed that there was no significant difference in the genotype distribution of 
WWOX polymorphisms between EGFR wild type and EGFR mutant in lung adenocarcinoma patients.

Table 1. Demographics and clinical characteristics of 316 patients in lung adenocarcinoma with EGFR mutation status.

\begin{tabular}{|c|c|c|c|}
\hline Variable & Wild Type $(N=127) n(\%)$ & EGFR Mutation $(N=189) n(\%)$ & $p$ Value \\
\hline \multicolumn{4}{|l|}{ Age } \\
\hline Mean \pm SD & $65.23 \pm 13.29$ & $66.32 \pm 13.44$ & $p=0.479$ \\
\hline \multicolumn{4}{|l|}{ Gender } \\
\hline Male & $79(62.6 \%)$ & $69(36.5 \%)$ & $p<0.001$ \\
\hline Female & $48(37.8 \%)$ & $120(63.5 \%)$ & \\
\hline \multicolumn{4}{|c|}{ Cigarette smoking status } \\
\hline Never-smoker & $55(43.3 \%)$ & $145(76.7 \%)$ & $p<0.001$ \\
\hline Ever-smoker & $72(56.7 \%)$ & $44(23.3 \%)$ & \\
\hline \multicolumn{4}{|l|}{ stage } \\
\hline $\mathrm{I}+\mathrm{II}$ & $29(22.8 \%)$ & $50(26.5 \%)$ & $p=0.466$ \\
\hline III + IV & $98(77.2 \%)$ & $139(73.5 \%)$ & \\
\hline \multicolumn{4}{|l|}{ Tumor T status } \\
\hline $\mathrm{T} 1+\mathrm{T} 2$ & $65(51.2 \%)$ & $115(60.8 \%)$ & $p=0.089$ \\
\hline $\mathrm{T} 3+\mathrm{T} 4$ & $62(48.8 \%)$ & $74(39.2 \%)$ & \\
\hline \multicolumn{4}{|l|}{ Lymph node status } \\
\hline Negative & $32(25.2 \%)$ & $60(31.7 \%)$ & $p=0.209$ \\
\hline Positive & $95(74.8 \%)$ & $129(68.3 \%)$ & \\
\hline \multicolumn{4}{|l|}{ Distant Metastasis } \\
\hline Negative & $59(46.5 \%)$ & $85(45.0 \%)$ & $p=0.795$ \\
\hline Positive & $68(53.5 \%)$ & $104(55.0 \%)$ & \\
\hline
\end{tabular}

Table 2. Distribution frequency of WWOX genotypes of 127 EGFR wild type and 189 EGFR mutation type in lung adenocarcinoma patients.

\begin{tabular}{|c|c|c|c|c|}
\hline Variable & Wild Type $(N=127)(\%)$ & Mutation Type $(N=189)(\%)$ & OR $(95 \% \mathrm{CI})$ & AOR $(95 \% \mathrm{CI})$ \\
\hline \multicolumn{5}{|l|}{ rs11545028 } \\
\hline $\mathrm{CC}$ & $72(56.7 \%)$ & $96(50.8 \%)$ & 1.00 & 1.00 \\
\hline $\mathrm{CT}$ & $44(34.6 \%)$ & $83(43.9 \%)$ & $1.415(0.879-2.278)$ & $1.610(0.860-3.013)$ \\
\hline TT & $11(8.7 \%)$ & $10(5.3 \%)$ & $0.682(0.275-1.693)$ & $0.757(0.222-2.578)$ \\
\hline $\mathrm{CT}+\mathrm{TT}$ & $55(43.3 \%)$ & $93(49.2 \%)$ & $1.268(0.807-1.993)$ & $1.446(0.796-2.626)$ \\
\hline \multicolumn{5}{|l|}{ rs12918952 } \\
\hline GG & $117(92.1 \%)$ & $172(91.0 \%)$ & 1.00 & 1.00 \\
\hline GA & $10(7.9 \%)$ & $14(7.4 \%)$ & $0.952(0.409-2.217)$ & $1.019(0.352-2.945)$ \\
\hline AA & $0(0 \%)$ & $3(1.6 \%)$ & - & - \\
\hline $\mathrm{GA}+\mathrm{AA}$ & $10(7.9 \%)$ & $17(9.0 \%)$ & $1.156(0.512-2.614)$ & $1.229(0.443-3.410)$ \\
\hline \multicolumn{5}{|l|}{ rs3764340 } \\
\hline $\mathrm{CC}$ & $107(84.3 \%)$ & $157(83.1 \%)$ & 1.00 & 1.00 \\
\hline CG & $18(14.2 \%)$ & $30(15.9 \%)$ & $1.136(0.603-2.141)$ & $1.315(0.585-2.955)$ \\
\hline GG & $2(1.5 \%)$ & $2(1.0 \%)$ & $0.682(0.095-4.913)$ & $1.195(0.099-14.461)$ \\
\hline $\mathrm{CG}+\mathrm{GG}$ & $20(15.7 \%)$ & $32(16.9 \%)$ & $0.966(0.763-1.225)$ & $1.304(0.599-2.836)$ \\
\hline \multicolumn{5}{|l|}{ rs73569323 } \\
\hline $\mathrm{CC}$ & $105(82.7 \%)$ & $166(87.8 \%)$ & 1.00 & 1.00 \\
\hline CT & $22(17.3 \%)$ & $23(12.2 \%)$ & $0.661(0.351-1.246)$ & $0.622(0.258-1.500)$ \\
\hline $\mathrm{TT}$ & $0(0 \%)$ & $0(0 \%)$ & - & - \\
\hline $\mathrm{CT}+\mathrm{TT}$ & $22(17.3 \%)$ & $23(12.2 \%)$ & $0.661(0.351-1.246)$ & $0.622(0.258-1.500)$ \\
\hline \multicolumn{5}{|l|}{ rs383362 } \\
\hline GG & $97(76.4 \%)$ & $155(82.0 \%)$ & 1.00 & 1.00 \\
\hline GT & $26(20.5 \%)$ & $32(16.9 \%)$ & $0.770(0.433-1.371)$ & $0.626(0.292-1.341)$ \\
\hline $\mathrm{TT}$ & $4(3.1 \%)$ & $2(1.1 \%)$ & $0.313(0.056-1.741)$ & $0.207(0.023-1.884)$ \\
\hline $\mathrm{GT}+\mathrm{TT}$ & $30(23.6 \%)$ & $34(18.0 \%)$ & $0.709(0.408-1.233)$ & $0.563(0.271-1.170)$ \\
\hline
\end{tabular}


We further studied the genotype distributions and associations of the WWOX gene in lung adenocarcinoma patients with two EGFR hotspot mutations, L858R $(n=89)$ and exon19 in-frame deletion $(n=91)$. In comparison with the EGFR wild type group, no significant association was found between WWOX polymorphisms and the two EGFR hotspot mutations in lung adenocarcinoma patients (Table 3).

Table 3. The associations between the polymorphisms of WWOX and the EGFR hotspot mutations in lung adenocarcinoma patients.

\begin{tabular}{|c|c|c|c|c|c|}
\hline \multirow{2}{*}{ Variable } & \multirow{2}{*}{$\begin{array}{c}\text { Wild Type } \\
(N=127)(\%)\end{array}$} & \multirow[b]{2}{*}{$(N=89)(\%)$} & \multirow{2}{*}{$\frac{\text { L858R }}{\text { OR }}$} & \multicolumn{2}{|c|}{ Exon 19 in-Frame Deletion } \\
\hline & & & & $(N=91)(\%)$ & OR $(95 \% \mathrm{CI})$ \\
\hline \multicolumn{6}{|l|}{ rs11545028 } \\
\hline $\mathrm{CC}$ & $72(56.7 \%)$ & $42(47.2 \%)$ & 1.00 & $51(56.0 \%)$ & 1.00 \\
\hline $\mathrm{CT}$ & $44(34.6 \%)$ & $44(49.4 \%)$ & $1.714(0.874-3.017)$ & $33(36.3 \%)$ & $1.059(0.595-1.885)$ \\
\hline TT & $11(8.7 \%)$ & $3(3.4 \%)$ & $0.263(0.468-1.772)$ & $7(7.7 \%)$ & $0.898(0.326-2.475)$ \\
\hline $\mathrm{CT}+\mathrm{TT}$ & $55(43.3 \%)$ & $47(52.8 \%)$ & $1.465(0.850-2.525)$ & $40(44.0 \%)$ & $1.027(0.597-1.767)$ \\
\hline \multicolumn{6}{|l|}{ rs12918952 } \\
\hline GG & $117(92.1 \%)$ & $80(89.9 \%)$ & 1.00 & $83(91.2 \%)$ & 1.00 \\
\hline GA & $10(7.9 \%)$ & $8(9.0 \%)$ & $1.170(0.443-3.093)$ & $6(6.6 \%)$ & $0.846(0.296-2.418)$ \\
\hline AA & $0(0 \%)$ & $1(1.1 \%)$ & - & $2(2.2 \%)$ & - \\
\hline $\mathrm{GA}+\mathrm{AA}$ & $10(7.9 \%)$ & $9(10.1 \%)$ & $1.316(0.512-3.384)$ & $8(8.8 \%)$ & $1.128(0.427-2.979)$ \\
\hline \multicolumn{6}{|l|}{ rs3764340 } \\
\hline $\mathrm{CC}$ & $107(84.3 \%)$ & $71(79.8 \%)$ & 1.00 & $78(85.7 \%)$ & 1.00 \\
\hline CG & $18(14.2 \%)$ & $16(18.0 \%)$ & $1.340(0.641-2.800)$ & $13(14.3 \%)$ & $0.991(0.458-2.141)$ \\
\hline GG & $2(1.5 \%)$ & $2(2.2 \%)$ & 1.507 (0.207-10.946) & $0(0 \%)$ & - \\
\hline $\mathrm{CG}+\mathrm{GG}$ & $20(15.7 \%)$ & $18(20.2 \%)$ & $1.356(0.671-2.742)$ & $13(14.3 \%)$ & $0.892(0.418-1.901)$ \\
\hline \multicolumn{6}{|l|}{ rs73569323 } \\
\hline $\mathrm{CC}$ & $105(82.7 \%)$ & $79(88.8 \%)$ & 1.00 & $78(85.7 \%)$ & 1.00 \\
\hline $\mathrm{CT}$ & $22(17.3 \%)$ & $10(11.2 \%)$ & $0.604(0.271-1.348)$ & $13(14.3 \%)$ & $0.795(0.377-1.677)$ \\
\hline TT & $0(0 \%)$ & $0(0 \%)$ & - & $0(0 \%)$ & - \\
\hline $\mathrm{CT}+\mathrm{TT}$ & $22(17.3 \%)$ & $10(11.2 \%)$ & $0.604(0.271-1.348)$ & $13(14.3 \%)$ & $0.795(0.377-1.677)$ \\
\hline \multicolumn{6}{|l|}{ rs383362 } \\
\hline GG & $97(76.4 \%)$ & $74(83.1 \%)$ & 1.00 & $72(79.1 \%)$ & 1.00 \\
\hline GT & $26(20.5 \%)$ & $13(14.6 \%)$ & $0.655(0.315-1.362)$ & $19(20.9 \%)$ & $0.985(0.506-1.915)$ \\
\hline $\mathrm{TT}$ & $4(3.1 \%)$ & $2(2.3 \%)$ & $0.655(0.117-3.675)$ & $0(0 \%)$ & - \\
\hline $\mathrm{GT}+\mathrm{TT}$ & $30(23.6 \%)$ & $15(16.9 \%)$ & $0.655(0.329-1.306)$ & $19(20.9 \%)$ & $0.853(0.445-1.635)$ \\
\hline
\end{tabular}

\subsection{Correlation between WWOX SNPs and the Tumor Classification in Lung} Adenocarcinoma Patients

Lung adenocarcinoma is staged according to the tumor/lymph node/metastasis (TNM) classification of the American Joint Committee on Cancer, an internationally recognized system [27]. Next, we studied the association between the frequency of WWOX genotype distribution and clinicopathological characteristics in the recruited patients. As shown in Table 4, it was found that WWOX rs3764340 was positively correlated with lymph node status in the EGFR mutation group. Compared with the CC genotype, the presence of at least one G genotype (CG and GG) allele on WWOX rs3764340 was associated with a significantly higher risk of nearby lymph node involvement in the patients harboring EGFR mutations ( $n=189$, OR: 3.881, 95\% CI: 1.295-11.629, $p=0.010$; Table 4).

We further performed a subgroup analysis based on the two EGFR hotspot mutations: L858R and Exon19 in-frame deletion. In the L858R subgroup, patients with at least one G genotype (CG and GG) of WWOX rs3764340 had the higher risk of nearby lymph nodes $(n=89, \mathrm{OR}=5.209,95 \% \mathrm{CI}=1.111-24.424, p=0.023$; Table 4). Compared with the CC genotype, at least G genotype (CG and GG) allele on WWOX rs3764340 also enhanced the risk of the tumor status, including the size of the primary tumor and the invasion of adjacent tissues in patients with EGFR L858R mutation $(\mathrm{OR}=3.681,95 \% \mathrm{CI}=1.259-10.757$, $p=0.014$; Table 4). Furthermore, we observed that rs73569323 carrying at least $\mathrm{T}$ genotype 
(CT and TT) allele was significant associated with tumor status of lung adenocarcinoma patients with EGFR L858R mutation ( $\mathrm{OR}=3.886,95 \% \mathrm{CI}=1.000-15.103, p=0.039$; Table 5). The data demonstrated that lung adenocarcinoma patients with EGFR L858R mutation, accompanied by WWOX rs73569323 C > T polymorphism, may show large tumor size and invasion of adjacent tissues.

Table 4. Associations between polymorphic genotypes of WWOX (rs3764340) and clinicopathologic characteristics of lung cancer with EGFR mutation.

\begin{tabular}{|c|c|c|c|c|c|c|c|c|c|}
\hline \multirow[b]{2}{*}{ Variable } & \multicolumn{3}{|c|}{ EGFR Mutation $(N=189)$} & \multicolumn{3}{|c|}{ L858R $(N=89)$} & \multicolumn{3}{|c|}{ Exon 19 in-Frame Deletion $(N=91)$} \\
\hline & $\begin{array}{c}\mathrm{CC} \\
(N=157)\end{array}$ & $\begin{array}{c}\text { CG + GG } \\
(N=32)\end{array}$ & $p$ Value & $\begin{array}{c}\text { CC } \\
(N=71)\end{array}$ & $\begin{array}{c}C G+\text { GG } \\
(N=18)\end{array}$ & $p$ Value & $\begin{array}{c}\mathrm{CC} \\
(N=78)\end{array}$ & $\begin{array}{c}C G+\text { GG } \\
(N=13)\end{array}$ & $p$ Value \\
\hline \multicolumn{10}{|l|}{ Stage } \\
\hline $\mathrm{I}+\mathrm{II}$ & $43(27.4 \%)$ & $7(21.9 \%)$ & $p=0.519$ & $22(31.0 \%)$ & $4(22.2 \%)$ & $p=0.465$ & $20(25.6 \%)$ & $3(23.1 \%)$ & $p=0.844$ \\
\hline $\mathrm{III}+\mathrm{IV}$ & $114(72.6 \%)$ & $25(78.1 \%)$ & & $49(69.0 \%)$ & $14(77.8 \%)$ & & $58(74.4 \%)$ & $10(76.9 \%)$ & \\
\hline \multicolumn{10}{|c|}{ Tumor T status } \\
\hline $\mathrm{T} 1+\mathrm{T} 2$ & $99(63.1 \%)$ & $16(50.0 \%)$ & $p=0.168$ & $53(74.6 \%)$ & $8(44.4 \%)$ & $p=0.014^{*, \mathrm{~b}}$ & $42(53.8 \%)$ & $8(61.5 \%)$ & $p=0.606$ \\
\hline $\mathrm{T} 3+\mathrm{T} 4$ & $58(36.9 \%)$ & $16(50.0 \%)$ & & $18(25.4 \%)$ & $10(55.6 \%)$ & & $36(46.2 \%)$ & $5(38.5 \%)$ & \\
\hline \multicolumn{10}{|c|}{ Lymph node status } \\
\hline Negative & $56(35.7 \%)$ & $4(12.5 \%)$ & $p=0.010 *, \mathrm{a}$ & $28(39.4 \%)$ & $2(11.1 \%)$ & $p=0.023^{*, \mathrm{c}}$ & $27(34.6 \%)$ & $2(15.4 \%)$ & $p=0.168$ \\
\hline Positive & $101(64.3 \%)$ & $28(87.5 \%)$ & & $43(60.6 \%)$ & $16(88.9 \%)$ & & $51(65.4 \%)$ & $11(84.6 \%)$ & \\
\hline \multicolumn{10}{|c|}{ Distant Metastasis } \\
\hline Negative & $71(45.2 \%)$ & $14(43.8 \%)$ & $p=0.879$ & $39(45.2 \%)$ & $8(43.8 \%)$ & $p=0.426$ & $29(37.2 \%)$ & $6(46.2 \%)$ & $p=0.538$ \\
\hline Positive & $86(54.8 \%)$ & $18(56.2 \%)$ & & $32(54.8 \%)$ & $10(56.2 \%)$ & & $49(62.8 \%)$ & $7(53.8 \%)$ & \\
\hline
\end{tabular}

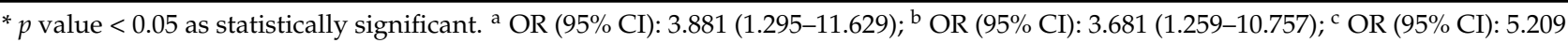
(1.111-24.424).

Table 5. Associations between polymorphic genotypes of WWOX (rs73569323) and clinicopathologic characteristics of lung cancer with EGFR mutation.

\begin{tabular}{|c|c|c|c|c|c|c|c|c|c|}
\hline \multirow[b]{2}{*}{ Variable } & \multicolumn{3}{|c|}{ EGFR Mutation $(N=189)$} & \multicolumn{3}{|c|}{ L858R $(N=89)$} & \multicolumn{3}{|c|}{ Exon 19 in-Frame Deletion $(N=91)$} \\
\hline & $\begin{array}{c}C C \\
(N=166)\end{array}$ & $\begin{array}{l}\text { CT + TT } \\
(N=23)\end{array}$ & $p$ Value & $\begin{array}{c}C C \\
(N=79)\end{array}$ & $\begin{array}{l}\text { CT + TT } \\
(N=10)\end{array}$ & $p$ Value & $\begin{array}{c}\text { CC } \\
(N=78)\end{array}$ & $\begin{array}{l}\mathrm{CT}+\mathrm{TT} \\
(N=13)\end{array}$ & $p$ Value \\
\hline Stage & & & \multirow{3}{*}{$p=0.293$} & & & \multirow{3}{*}{$p=0.954$} & & & \multirow{3}{*}{$p=0.115$} \\
\hline $\mathrm{I}+\mathrm{II}$ & $46(27.7 \%)$ & $4(17.4 \%)$ & & $23(29.1 \%)$ & $3(30.0 \%)$ & & $2(28.2 \%)$ & $1(7.7 \%)$ & \\
\hline III + IV & $120(72.3 \%)$ & $19(82.6 \%)$ & & $56(70.9 \%)$ & $7(70.0 \%)$ & & $56(71.8 \%)$ & $12(92.3 \%)$ & \\
\hline \multicolumn{10}{|c|}{ Tumor T status } \\
\hline $\mathrm{T} 1+\mathrm{T} 2$ & $105(63.3 \%)$ & $10(43.5 \%)$ & \multirow[t]{2}{*}{$p=0.069$} & $57(72.2 \%)$ & $4(40.0 \%)$ & \multirow[t]{2}{*}{$p=0.039^{*, a}$} & $44(56.4 \%)$ & $6(46.2 \%)$ & \multirow[t]{2}{*}{$p=0.491$} \\
\hline $\mathrm{T} 3+\mathrm{T} 4$ & $61(36.7 \%)$ & $13(56.5 \%)$ & & $22(27.8 \%)$ & $6(60.0 \%)$ & & $34(43.6 \%)$ & $7(53.8 \%)$ & \\
\hline \multicolumn{10}{|c|}{ Lymph node status } \\
\hline Negative & $54(32.5 \%)$ & $6(26.1 \%)$ & \multirow[t]{2}{*}{$p=0.534$} & $27(34.2 \%)$ & $3(30.0 \%)$ & \multirow[t]{2}{*}{$p=0.792$} & $26(33.3 \%)$ & $3(23.1 \%)$ & \multirow[t]{2}{*}{$p=0.462$} \\
\hline Positive & $112(67.5 \%)$ & $17(73.9 \%)$ & & $52(65.8 \%)$ & $7(70.0 \%)$ & & $52(66.7 \%)$ & $10(76.9 \%)$ & \\
\hline \multicolumn{10}{|c|}{ Distant Metastasis } \\
\hline Negative & $78(47.0 \%)$ & $7(30.4 \%)$ & \multirow{2}{*}{$p=0.135$} & $43(54.4 \%)$ & $4(40.0 \%)$ & \multirow[t]{2}{*}{$p=0.389$} & $32(41.0 \%)$ & $3(23.1 \%)$ & \multirow[t]{2}{*}{$p=0.218$} \\
\hline Positive & $7(53.0 \%)$ & $16(69.6 \%)$ & & $36(45.6 \%)$ & $6(60.0 \%)$ & & $46(59.0 \%)$ & $10(76.9 \%)$ & \\
\hline
\end{tabular}

${ }^{*} p$ value $<0.05$ as statistically significant. ${ }^{a}$ OR $(95 \% \mathrm{CI}): 3.886$ (1.000-15.103).

\section{Discussion}

In the present study, we found that the frequency of WWOX SNPs rs11545028, rs12918952, rs3764340, rs73569323, and rs383362 was not significantly different between wild-type and mutant EGFR lung adenocarcinoma patients. The existence of at least one $G$ genotype (CG and GG) allele on WWOX rs3764340 exhibited a significant association with the involvement of nearby lymph nodes in the lung adenocarcinoma patients harboring EGFR mutations, particularly those with the EGFR L858R mutation. In the lung adenocarcinoma patients with the EGFR L858R mutation, the WWOX rs3764340 G genotype or rs73569323 T genotype of WWOX was shown to be associated with a significantly increase of primary tumor size and invasion of adjacent tissues. Our data suggest-that examining WWOX SNPs, rs3764340 and rs73569323, may help identify patients with lung adenocarcinoma with EGFR L858R mutations that have a higher risk of tumor size $(\mathrm{T})$ and affected lymph node $(\mathrm{N})$ status.

WWOX has been proven to perform tumor suppression through several molecular mechanisms in different cancers and diseases. The germline inactivation of the WWOX gene through homologous deletion can lead to human autosomal recessive diseases, such 
as the WWOX-related epileptic encephalopathy syndrome [15]. Iliopoulos et al. [29] show that changes in WWOX expression in lung, breast, and bladder cancers are not only due to genomic alterations, such as loss of heterozygosity and homozygous deletions, but also epigenetic modifications, such as promoter hypermethylation. WWOX allele deletions have been found in $30.0 \%$ (three out of ten) lung adenocarcinomas [17]. Indeed, the incidence of WWOX exon 6-8 deletion is reported to be high in Chinese NSCLC patients [30]. Furthermore, hypermethylation in the promoter region of WWOX gene and mutation of this gene may be related to NSCLC carcinogenesis [31]. Donati et al. [19] shows that WWOX protein is lost or reduced in most NSCLCs and loss of WWOX expression is associated with to highly aggressive tumors using immunohistochemistry analysis. Multiple pathogenic copy number variations spanning of WWOX have been identified associated with neurological conditions [32]. Here, we found that WWOX SNPs exhibited significant associations with the size of the primary tumor and the invasion of adjacent tissues in patients with EGFR mutant lung adenocarcinoma, especially those with EGFRL858R mutant.

Lung adenocarcinoma has been shown to be related to many risk factors, such as genetic and environmental factors. Previous studies have shown that EGFR gene mutations occur more frequently in Asians than in Caucasians [33]. Furthermore, the significant differences in gender and smoking status of the lung adenocarcinoma patients recruited in this study were similar to previous studies. That is, lung adenocarcinoma has been found to occur more frequently in non-smokers and Asian women [34,35]. The genotype distribution of WWOX polymorphisms showed no significant difference between wild type and mutant EGFR in lung adenocarcinoma patients. The FRA16D fragile region, which contains the WWOX gene, is a hot spot for genomic instability, prone to chromosomal breakage and copy number variations $[9,10]$. The use of sequencing analysis has found high levels of SNPs in the WWOX gene and several missense polymorphisms in cancer cell lines and tumor tissues [36]. Here we showed that two WWOX SNPs, rs3764340 C/G and rs73569323 C/T, are highly associated with large tumor size and invasion of adjacent tissues in patients with EGFR-L858R mutant lung adenocarcinoma. However, we did not observe the association between the other WWOX SNPs and the risk of lung adenocarcinoma, which may be attributed to the limited samples.

We found that the lung adenocarcinoma patients with both EGFR mutation and WWOX rs3764340 C/G polymorphism may be prone to the involvement of nearby lymph nodes, especially those with EGFR L858R mutation. In patients with EGFR-L858R mutant lung adenocarcinoma, WWOX rs3764340 C/G polymorphism is also associated with tumor growth and invasion. Previous studies have shown that the C/G genotype of WWOX rs3764340 is highly associated with differentiated thyroid carcinoma [20], elevated grade and metastasis risk of osteosarcoma [25], and is susceptible to cervical invasive cancer [37]. The rs3764340 C/G polymorphism causes the amino acid at codon 282 of WWOX to replace proline to alanine. We speculate that the variant allele 282 may affect the biological functions of WWOX, thereby making individuals susceptible to cancer.

Our data demonstrated that WWOX rs73569323 polymorphism is positively associated with tumor size and invasion in patients with EGFR-L858R mutant lung adenocarcinoma. In contrast, WWOX rs73569323 SNP is found to decrease the risk of hepatocellular carcinoma [26]. The rs73569323 SNP is located in the $3^{\prime}$ untranslated region (UTR), which is usually one of the microRNA (miRNA) target regions. MiRNAs that negatively regulate the expression of target genes have an important regulatory role in carcinogenesis [38]. In head and neck squamous cell carcinoma (HNSCC), miR-134 expression was reversely associated with the WWOX expression in clinical HNSCC tissues and miR-134 directly targets the $3^{\prime}$ UTR of WWOX gene in HNSCC cells [39]. Interestingly, Chen et al. [40] show that the transfection of miR-134 mimics decreased the level of WWOX, whereas, anti-miR134 increased WWOX expression in the small cell lung cancer cells. In addition, miR-24 also directly binds to the $3^{\prime}$ UTR of WWOX gene to inhibit gene expression in NSCLC 
cells [41]. Therefore, WWOX rs73569323 SNP may affect the various miRNA binding to $3^{\prime}$ UTR, leading to different expression and function of WWOX in different cancer types.

There are some limitations in the present study. Further studies on larger cohorts are needed to confirm the association between these WWOX SNPs and the clinicopathological characteristics of patients with lung adenocarcinoma. Since our study only analyzes the Taiwanese patient group, it may be necessary to conduct larger population-based studies in different ethnic groups for verification in the future. Moreover, it is necessary to study whether these polymorphic changes alter the function of WWOX protein in EGFR-mutated lung adenocarcinoma patients, especially L858R-mutated lung adenocarcinoma patients.

\section{Conclusions}

The present results indicate that WWOX rs3764340 SNP is associated with a significantly increased risk of lymph node involvement in patients with lung adenocarcinoma carrying EGFR mutations. In addition, WWOX rs3764340 and rs73569323 polymorphisms are highly correlated with the size of the primary tumor and the invasion of adjacent tissues in Taiwanese lung adenocarcinoma patients carrying the EGFR-L858R mutation gene. Our data suggest that WWOX SNPs may help to predict tumor growth and invasion in patients with EGFR mutant lung adenocarcinoma, especially those with the EGFR-L858R mutant. In Taiwanese patients with EGFR-mutant lung adenocarcinoma, especially those with EGFR-L858R gene mutation, the underlying mechanism of the WWOX signaling cascade dysregulation is worthy of further exploration.

Author Contributions: Conceptualization, J.-P.L., J.T.C., M.-J.H. and S.-F.Y.; formal analysis, P.-C.J., M.-H.H., Y.-H.C. and S.-F.Y.; resources, T.C.-Y.T. and S.-F.Y.; writing — original draft preparation, J.-P.L. and S.-F.Y.; writing — review and editing, J.-P.L., J.T.C., M.-J.H. and S.-F.Y. All authors have read and agreed to the published version of the manuscript.

Funding: This research was funded by Chung Shan Medical University, Taichung, Taiwan (RD10901).

Institutional Review Board Statement: The study protocol was approved by the Institutional Review Board of Chung Shan Medical University Hospital (No. CS1-20144, 24 August 2020).

Informed Consent Statement: Informed consent was obtained from all subjects involved in the study.

Data Availability Statement: The datasets generated for this study are available on request to the corresponding authors.

Acknowledgments: We would like to thank the Human Biobank of Chung Shan Medical University Hospital for providing the biological specimen and related clinical data for our research.

Conflicts of Interest: The authors declare no conflict of interest.

\section{References}

1. Siegel, R.L.; Miller, K.D.; Jemal, A. Cancer statistics, 2019. CA Cancer J. Clin. 2019, 69, 7-34. [CrossRef] [PubMed]

2. da Cunha Santos, G.; Shepherd, F.A.; Tsao, M.S. EGFR mutations and lung cancer. Annu. Rev. Pathol. 2011, 6, 49-69. [CrossRef]

3. Gazdar, A.F. Activating and resistance mutations of EGFR in non-small-cell lung cancer: Role in clinical response to EGFR tyrosine kinase inhibitors. Oncogene 2009, 28, S24-S31. [CrossRef] [PubMed]

4. Ladanyi, M.; Pao, W. Lung adenocarcinoma: Guiding EGFR-targeted therapy and beyond. Mod. Pathol. 2008, 21, S16-S22. [CrossRef]

5. Rosell, R.; Moran, T.; Queralt, C.; Porta, R.; Cardenal, F.; Camps, C.; Majem, M.; Lopez-Vivanco, G.; Isla, D.; Provencio, M.; et al. Screening for Epidermal Growth Factor Receptor Mutations in Lung Cancer. N. Engl. J. Med. 2009, 361, 958-967. [CrossRef]

6. Salah, Z.; Alian, A.; Aqeilan, R.I. WW domain-containing proteins: Retrospectives and the future. Front Biosci. 2012, 17, 331-348. [CrossRef]

7. Del Mare, S.; Salah, Z.; Aqeilan, R.I. WWOX: Its genomics, partners, and functions. J. Cell. Biochem. 2009, 108, 737-745. [CrossRef]

8. Bednarek, A.K.; Laflin, K.J.; Daniel, R.L.; Liao, Q.; Hawkins, K.A.; Aldaz, C.M. WWOX, a Novel WW Domain-containing Protein Mapping to Human Chromosome 16q23.3-24.1, a Region Frequently Affected in Breast Cancer. Cancer Res. 2000, 60, 2140.

9. Ried, K.; Finnis, M.; Hobson, L.; Mangelsdorf, M.; Dayan, S.; Nancarrow, J.K.; Woollatt, E.; Kremmidiotis, G.; Gardner, A.; Venter, D.; et al. Common chromosomal fragile site FRA16D sequence: Identification of the FOR gene spanning FRA16D and homozygous deletions and translocation breakpoints in cancer cells. Hum. Mol. Genet. 2000, 9, 1651-1663. [CrossRef] [PubMed] 
10. Lee, C.S.; Choo, A.; Dayan, S.; Richards, R.I.; O'Keefe, L.V. Molecular Biology of the WWOX Gene That Spans Chromosomal Fragile Site FRA16D. Cells 2021, 10, 1637. [CrossRef]

11. Salah, Z.; Aqeilan, R.; Huebner, K. WWOX gene and gene product: Tumor suppression through specific protein interactions. Future Oncol. 2010, 6, 249-259. [CrossRef] [PubMed]

12. Aqeilan, R.I.; Croce, C.M. WWOX in biological control and tumorigenesis. J. Cell. Physiol. 2007, 212, 307-310. [CrossRef] [PubMed]

13. Abu-Remaileh, M.; Joy-Dodson, E.; Schueler-Furman, O.; Aqeilan, R.I. Pleiotropic Functions of Tumor Suppressor WWOX in Normal and Cancer Cells. J. Biol. Chem. 2015, 290, 30728-30735. [CrossRef] [PubMed]

14. Tanna, M.; Aqeilan, R.I. Modeling WWOX Loss of Function in vivo: What Have We Learned? Front. Oncol. 2018, 8, 420. [CrossRef]

15. Taouis, K.; Driouch, K.; Lidereau, R.; Lallemand, F. Molecular Functions of WWOX Potentially Involved in Cancer Development. Cells 2021, 10, 1051. [CrossRef]

16. Pospiech, K.; Płuciennik, E.; Bednarek, A.K. WWOX Tumor Suppressor Gene in Breast Cancer, a Historical Perspective and Future Directions. Front. Oncol. 2018, 8, 345. [CrossRef]

17. Yendamuri, S.; Kuroki, T.; Trapasso, F.; Henry, A.C.; Dumon, K.R.; Huebner, K.; Williams, N.N.; Kaiser, L.R.; Croce, C.M. WW domain containing oxidoreductase gene expression is altered in non-small cell lung cancer. Cancer Res. 2003, 63, 878-881.

18. Pimenta, F.J.; Gomes, D.A.; Perdigão, P.F.; Barbosa, A.A.; Romano-Silva, M.A.; Gomez, M.V.; Aldaz, C.M.; De Marco, L.; Gomez, R.S. Characterization of the tumor suppressor gene WWOX in primary human oral squamous cell carcinomas. Int. J. Cancer 2006, 118, 1154-1158. [CrossRef]

19. Donati, V.; Fontanini, G.; Dell; Omodarme, M.; Prati, M.C.; Nuti, S.; Lucchi, M.; Mussi, A.; Fabbri, M.; Basolo, F.; et al. WWOX Expression in Different Histologic Types and Subtypes of Non-Small Cell Lung Cancer. Clin. Cancer Res. 2007, 13, 884. [CrossRef]

20. Cancemi, L.; Romei, C.; Bertocchi, S.; Tarrini, G.; Spitaleri, I.; Cipollini, M.; Landi, D.; Garritano, S.; Pellegrini, G.; Cristaudo, A.; et al. Evidences that the polymorphism Pro-282-Ala within the tumor suppressor gene WWOX is a new risk factor for differentiated thyroid carcinoma. Int. J. Cancer 2011, 129, 2816-2824. [CrossRef] [PubMed]

21. Zheng, Q.W.; Zhou, Y.L.; You, Q.J.; Shou, F.; Pang, Q.F.; Chen, J.L. WWOX inhibits the invasion of lung cancer cells by downregulating RUNX2. Cancer Gene Ther. 2016, 23, 433-438. [CrossRef] [PubMed]

22. Khawaled, S.; Nigita, G.; Distefano, R.; Oster, S.; Suh, S.-S.; Smith, Y.; Khalaileh, A.; Peng, Y.; Croce, C.M.; Geiger, T.; et al. Pleiotropic tumor suppressor functions of WWOX antagonize metastasis. Signal Transduct. Target. Ther. 2020, 5, 43. [CrossRef] [PubMed]

23. Deng, N.; Zhou, H.; Fan, H.; Yuan, Y. Single nucleotide polymorphisms and cancer susceptibility. Oncotarget 2017, 8, 110635-110649. [CrossRef]

24. Cheng, H.-L.; Liu, Y.-F.; Su, C.-W.; Su, S.-C.; Chen, M.-K.; Yang, S.-F.; Lin, C.-W. Functional genetic variant in the Kozak sequence of WW domain-containing oxidoreductase (WWOX) gene is associated with oral cancer risk. Oncotarget 2016, 7, 69384-69396. [CrossRef] [PubMed]

25. Zhang, N.; Jiang, Z.; Ren, W.; Yuan, L.; Zhu, Y. Association of polymorphisms in WWOX gene with risk and outcome of osteosarcoma in a sample of the young Chinese population. Onco. Targets Ther. 2016, 9, 807-813. [CrossRef]

26. Lee, H.-L.; Cheng, H.-L.; Liu, Y.-F.; Chou, M.-C.; Yang, S.-F.; Chou, Y.-E. Functional genetic variant of WW domain-containing oxidoreductase (WWOX) gene is associated with hepatocellular carcinoma risk. PLoS ONE 2017, 12, e0176141. [CrossRef]

27. Goldstraw, P.; Chansky, K.; Crowley, J.; Rami-Porta, R.; Asamura, H.; Eberhardt, W.E.; Nicholson, A.G.; Groome, P.; Mitchell, A.; Bolejack, V.; et al. The IASLC Lung Cancer Staging Project: Proposals for Revision of the TNM Stage Groupings in the Forthcoming (Eighth) Edition of the TNM Classification for Lung Cancer. J. Thorac. Oncol. 2016, 11, 39-51. [CrossRef] [PubMed]

28. Chang, J.H.; Lai, T.C.; Yang, P.J.; Shih, P.C.; Yang, Y.C.; Lee, K.L.; Liu, T.C.; Tsao, T.C.; Yang, S.F.; Chien, M.H. Associations of TIMP-3 Genetic Polymorphisms with EGFR Statuses and Cancer Clinicopathologic Development in Lung Adenocarcinoma Patients. Int. J. Mol. Sci. 2020, 21, 8023. [CrossRef]

29. Iliopoulos, D.; Guler, G.; Han, S.Y.; Johnston, D.; Druck, T.; McCorkell, K.A.; Palazzo, J.; McCue, P.A.; Baffa, R.; Huebner, K. Fragile genes as biomarkers: Epigenetic control of WWOX and FHIT in lung, breast and bladder cancer. Oncogene 2005, 24, 1625-1633. [CrossRef]

30. Zhou, Y.; Xu, Y.; Zhang, Z. Deletion and mutation of WWOX exons 6-8 in human non-small cell lung cancer. J. Huazhong Univ. Sci. Technol. 2005, 25, 162-165. [CrossRef]

31. Baykara, O.; Demirkaya, A.; Kaynak, K.; Tanju, S.; Toker, A.; Buyru, N. WWOX gene may contribute to progression of non-smallcell lung cancer (NSCLC). Tumour. Biol. 2010, 31, 315-320. [CrossRef]

32. Aldaz, C.M.; Hussain, T. WWOX Loss of Function in Neurodevelopmental and Neurodegenerative Disorders. Int. J. Mol. Sci. 2020, 21, 8922. [CrossRef]

33. Midha, A.; Dearden, S.; McCormack, R. EGFR mutation incidence in non-small-cell lung cancer of adenocarcinoma histology: A systematic review and global map by ethnicity (mutMapII). Am. J. Cancer Res. 2015, 5, 2892-2911.

34. de Groot, P.M.; Wu, C.C.; Carter, B.W.; Munden, R.F. The epidemiology of lung cancer. Transl. Lung Cancer Res. $2018,7,220-233$. [CrossRef] [PubMed]

35. Hsu, C.H.; Tseng, C.H.; Chiang, C.J.; Hsu, K.H.; Tseng, J.S.; Chen, K.C.; Wang, C.L.; Chen, C.Y.; Yen, S.H.; Chiu, C.H.; et al. Characteristics of young lung cancer: Analysis of Taiwan's nationwide lung cancer registry focusing on epidermal growth factor receptor mutation and smoking status. Oncotarget 2016, 7, 46628-46635. [CrossRef] 
36. Paige, A.J.; Taylor, K.J.; Taylor, C.; Hillier, S.G.; Farrington, S.; Scott, D.; Porteous, D.J.; Smyth, J.F.; Gabra, H.; Watson, J.E. WWOX: A candidate tumor suppressor gene involved in multiple tumor types. Proc. Natl. Acad. Sci. USA 2001, 98, 11417-11422. [CrossRef]

37. Lin, Y.H.; Hsiao, Y.H.; Wu, W.J.; Yang, S.F.; Hsu, C.F.; Kang, Y.T.; Wang, P.H. Relationship of genetic variant distributions of WW domain-containing oxidoreductase gene with uterine cervical cancer. Int. J. Med. Sci. 2018, 15, 1005-1013. [CrossRef]

38. Bartel, D.P. MicroRNAs: Target recognition and regulatory functions. Cell 2009, 136, 215-233. [CrossRef]

39. Liu, C.J.; Shen, W.G.; Peng, S.Y.; Cheng, H.W.; Kao, S.Y.; Lin, S.C.; Chang, K.W. miR-134 induces oncogenicity and metastasis in head and neck carcinoma through targeting WWOX gene. Int. J. Cancer 2014, 134, 811-821. [CrossRef]

40. Chen, T.; Gao, F.; Feng, S.; Yang, T.; Chen, M. MicroRNA-134 regulates lung cancer cell H69 growth and apoptosis by targeting WWOX gene and suppressing the ERK1/2 signaling pathway. Biochemical. Biophys. Res. Commun. 2015, 464, 748-754. [CrossRef]

41. Wang, X.-H.; Gan, C.-Z.; Xie, J.-Y. Inhibition of miR-24 suppresses malignancy of human non-small cell lung cancer cells by targeting WWOX in vitro and in vivo. Thorac. Cancer 2018, 9, 1583-1593. [CrossRef] [PubMed] 